\title{
Geological storage capacity for green excess energy readily available in Germany
}

\author{
Michael Kühn ${ }^{1,2}$, Natalie C. Nakaten ${ }^{1}$, and Thomas Kempka ${ }^{1,2}$ \\ ${ }^{1}$ GFZ German Research Centre for Geosciences, Fluid Systems Modelling, 14473 Potsdam, Germany \\ ${ }^{2}$ Institute of Geosciences, University of Potsdam, 14476 Potsdam, Germany
}

Correspondence: Michael Kühn (michael.kuehn@gfz-potsdam.de)

Received: 12 June 2020 - Revised: 5 October 2020 - Accepted: 6 November 2020 - Published: 3 December 2020

\begin{abstract}
Energy supply in Germany is subject to a profound change. The present paper addresses the German potential of storing excess energy from renewable power sources in the geological subsurface. Wind and solar electricity can be transformed into hydrogen, and with carbon dioxide subsequently into methane. When needed, electricity is regained in a gas turbine power plant combusting the methane. Here, we are taking into account the actual German storage capacity for natural gas and show that the outlined technology is ready for operation and economically competitive. The current potential for combined storage of methane and carbon dioxide allows to store around $80 \mathrm{TWh}$ renewable excess energy. This is far more than required to date and estimated to provide the entire coverage in 2050.
\end{abstract}

\section{Introduction}

The Paris Climate Agreement is based on numerous scientific findings on the causes of climate change and emphasises the increasingly apparent and serious impact of anthropogenic contributions (Luderer et al., 2018). However, the steps that the signatory states will have to take to achieve the selfimposed targets of the agreement are significant (acatech, 2018). The energy supply in Germany is subject to profound change (Henning and Palzer, 2014; Hartmann et al., 2012). Therefore, the present paper addresses the German potential for the innovative idea of storing excess energy from renewable power sources by synthetic natural gas (SNG), applying the "Power-to-Gas" (P2G) technology in an environmentalfriendly manner (Kühn, 2013).

P2G technologies offer a promising long-term storage approach for converting renewable electricity into a chemical form to serve the energy demands in related end-use sectors. Gorre et al. (2020) outline that P2G is widely and deeply developed, and at the edge of a mass roll-out. They state that the remaining barriers are no longer technical, but regulatory and economic.

With P2G, excess wind and solar electricity is transformed into hydrogen $\left(\mathrm{H}_{2}\right)$, and with carbon dioxide $\left(\mathrm{CO}_{2}\right)$ subsequently into methane $\left(\mathrm{CH}_{4}\right.$ - synthetic natural gas) or colloquially called "wind or solar gas". When needed, electricity can be regained in a gas turbine power plant combusting the methane, extending P2G to "Power-to-Gas-to-Power" (PGP; Sterner and Stadler, 2017). To close the carbon cycle, carbon dioxide is captured on site. Thus, geological subsurface storage for both gases is required for the technology (Kühn et al., 2013). With a regional show case for the city of Potsdam (Brandenburg, Germany), we were able to prove the overall energy and cost efficiency (Streibel et al., 2013).

Within the present study, we are taking into account the actual German storage capacity in operation for natural gas (EID, 2019). We investigate the technology to store excess energy in form of methane and to convert it into electricity via PGP based on the actual demand, and we update the classification of the PGP competitiveness on the global energy market. The questions to be answered are: how much storage capacity is already available in the German geological subsurface for such operation and how competitive is the proposed technology? 


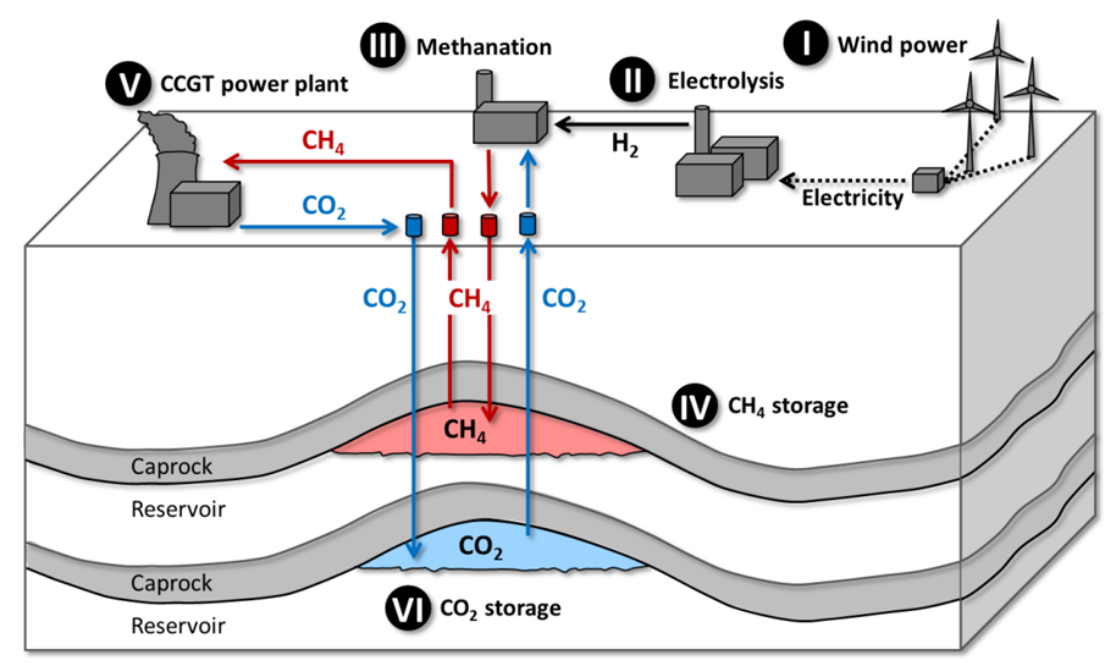

Figure 1. Schematic of the PGP cycle integrated with geological storage to decarbonise the conventional P2G technology.

\section{Material and methods}

\subsection{Power-to-Gas-to-Power Technology}

An innovative approach that complies with essential demands of the European Strategic Energy Technology Plan (SET Plan) is the patented PGP technology, an extension of the conventional P2G concept. This "system and method for ecologically generating and storing electricity" (Kühn, 2013) considers the conversion of excess renewable energy to hydrogen, and subsequently to methane by using carbon dioxide that is maintained in a closed cycle (Fig. 1).

If the current electricity demand is lower than its production from renewable sources, excess electricity from, e.g., wind power (i), is transformed into $\mathrm{H}_{2}$ (ii) and then into $\mathrm{CH}_{4}$ using $\mathrm{CO}_{2}$ (iii). $\mathrm{CH}_{4}$ is stored in a reservoir in the geological subsurface (iv) and electrified on demand (v) in a Combined-Cycle Gas Turbine power plant (CCGT). $\mathrm{CO}_{2}$ is captured from the CCGT power plant's flue gas and stored in a secondary subsurface reservoir (vi), closing the carbon cycle. The added value of a closed carbon cycle by capturing and temporarily storing $\mathrm{CO}_{2}$ in a subsurface reservoir results from $\mathrm{CO}_{2}$ being always at hand when excess energy needs to be transformed into $\mathrm{CH}_{4}$ (Fig. 1).

Energy storage on the basis of methane offers three major advantages over hydrogen storage: (i) it represents the current state-of-the-art and can be applied immediately, (ii) retransformation of methane into electricity can make use of established power plant technologies, and (iii) methane can be easily fed into the existing natural gas network. This is why an essential contribution to the electricity market in Germany and in Europe can be expected (Kühn et al., 2014a).

CCGT power plants are advantageous, because they can be flexibly started up and shut down for load balancing and base load provision in the electricity network. Furthermore, the power output is scalable over a range between 80 and
400 MW per block, what makes the system profitable even for smaller units. Hence, decentralisation and control of electricity in "smart grids" is supported (Streibel et al., 2013; Sterner and Stadler, 2017).

The overall efficiency of the PGP approach is given by Streibel et al. (2013) based on chemical energies taking into account reaction enthalpies for all process steps included. Therein, methanization is presumed with an efficiency of $80 \%$ and electrolysis as well with $80 \%$ (DVGW, 2014). CCGT is based on a $60 \%$ efficiency (Nakaten et al., 2014), reduced by the energy loss of $8 \%$ due to coupled $\mathrm{CO}_{2}$ capture with an efficiency of $90 \%$ (Metz et al., 2005). The result is a total efficiency of the entire PGP process of $26 \%$. This is without the provision of residual heat, which would further increase the efficiency. It is important to note that subsurface storage is literally insignificant for the overall efficiency causing a loss of only $0.2 \%$ (Streibel et al., 2013).

In addition, it is shown that one subsurface storage reservoir for both gases, $\mathrm{CH}_{4}$ and $\mathrm{CO}_{2}$, in combination with the proven Enhanced Gas Recovery (EGR) operation provides an alternative option for the outlined concept (Kühn et al., 2014b). EGR helps to maintain and manage the reservoir pressure, increase the sweep efficiency and production rates (Metz et al., 2005). In fact, EGR works in both directions. On the one hand, $\mathrm{CO}_{2}$ injection enhances $\mathrm{CH}_{4}$ recovery, and on the other hand $\mathrm{CH}_{4}$ injection displaces $\mathrm{CO}_{2}$ equally efficient (van der Meer, 2005). The ideal depth for EGR is expected to start at $700 \mathrm{~m}$, where $\mathrm{CO}_{2}$ density and viscosity start to notably increase depending on temperature and pressure. The biggest jump in density occurs between 70 and 90 bar. The increase of both values for $\mathrm{CH}_{4}$ is gradual and substantially lower within this range. The larger the difference in density and viscosity of both gases, the lower the occurring gas component mixing. However, mixing of both gases in the reservoir is inevitable and needs to be minimised to optimise the 
efficiency of single-reservoir P2G systems. Feasible injection rates and injection schedules can be derived from an integrated reservoir stability analysis (Ma et al., 2019).

\subsection{Geological subsurface gas storage in Germany}

The State Office for Mining, Energy and Geology of Lower Saxony (LBEG, Hannover) annually compiles relevant data from industry. The statistical and descriptive information about the natural gas storage serves companies and politics as a source of evidence and information. More than 40 subsurface storage sites for natural gas exist in Germany to date (EID, 2019). They provide a total storage capacity of around 24 billion $\mathrm{sm}^{3}$ (= standard cubic metres) of $\mathrm{CH}_{4}$ working gas, which represents an energy equivalent of around $240 \mathrm{TWh}$ (specific calorific value of approximately 9.8 to $11.5 \mathrm{kWh} \mathrm{m}^{-3}$ depending on the average gas quality). These sites are either porous formations (16 in operation, $38 \%$ of total working gas volume) or caverns in salt structures (31 in operation, $62 \%$ of total working gas volume). As caverns are assumed to be almost completely gas-tight, they should probably be preferred for $\mathrm{H}_{2}$ storage in the near future. Therefore, our estimate is solely based on the existing and operating 16 storage sites in porous media (Table 1). The working gas volume of these sites is around 9 billion standard $\mathrm{m}^{3}$ with an energy equivalent of $90 \mathrm{TWh}$. The total gas volume stored in porous media is around 18 billion standard $\mathrm{m}^{3}$, representing an average ratio of $50 \%$ working gas to $50 \%$ cushion gas. The depth of the 16 storage sites ranges from $350 \mathrm{~m}$ down to $2930 \mathrm{~m}$ and the reservoirs used are either saline aquifers or former oil and natural gas deposits. Reservoirs in former gas deposits are of pronounced importance for the German storage capacity in porous media (Table 1). The advantage of former deposits is the excellent data basis for the description of the reservoirs and their caprocks, and thus the deduction of potential overall storage performances. The respective sandstone formations are located in the sedimentary basins of North, East and Southern Germany (EID, 2019).

\subsection{Update of the competitiveness of the technology on the energy market}

Our previous economic assessments have shown that PGP is economically competitive compared to conventional storage technologies, whereby its efficiency still requires optimization (Streibel et al., 2013; Kühn et al., 2014a, b). Hereby, energy production and storage technology economics used in the previous assessment originate from the year 2012. However, cost trends related to energy production and storage significantly correlate with fuel and commodity prices. For example, $\mathrm{CO}_{2}$ emission charges as well as technology improvements rapidly changed in the past few years. Therefore, we update the classification of the PGP competitiveness within the presented study.

\section{Results}

\subsection{Readily available geological subsurface storage capacity}

The answer to the question how much storage capacity is already available in the German geological subsurface is based on the sites in operation (EID, 2019; Table 1). In view of an EGR process, it is outlined that the preferable depth for the mutual displacement of $\mathrm{CH}_{4}$ and $\mathrm{CO}_{2}$ is $700 \mathrm{~m}$ and below (Kühn et al., 2014b). This reduces the number of suitable storage sites (Table 1) to 10 of 16 with a total working gas volume of around 8.7 billion standard $\mathrm{m}^{3}$, representing an energy equivalent of more than $80 \mathrm{TWh}$. Following this criterion, the suitable German sites are Bad Lauchstädt, Bierwang, BreitbrunnEggstätt, Frankenthal, Fronhofen-Illmensee, Inzenham, Rehden, Schmidhausen, Uelsen and Wolfersberg (Table 1), whereas the reservoirs of Allmenhausen, Eschenfelden, Hähnlein, Sandhausen and Stockstadt are too shallow. Except for the site Frankenthal, representing a saline aquifer and Fronhofen-Illmensee, located in a former oil deposit, the other seven candidate sites use reservoirs in former gas deposits.

Feed-in management refers to regulations that are applied to renewable energy systems, so that electricity produced cannot be fed into the power grid. Restrictions are necessary if parts of the power grid are overloaded. The majority of the regulated amount of electricity comes from wind energy. In 2017 and 2018, over 5 TWh of wind energy had to be curtailed (Renewable Energies Agency, 2020). However, instead of regulating systems, it would make more sense to store the electricity. The described technology provides in that way much more than the capacity needed at the moment. Sterner and Stadler (2017) compare ten different scenarios for the energy market of Germany and estimate an average of just below $80 \mathrm{TWh}$ excess energy and required storage capacity for the year 2050. The presented numbers show that this demand can be covered by geological storage.

\subsection{Competitiveness on the global energy market}

The answer to the question how competitive the technology is, was derived based on cost data applied to ascertain current and future market trends from different literature sources. Cost of electricity (COE) bandwidths for photovoltaic (4 to 22 eurocents per $\mathrm{kWh}$ ), solar thermal power (4 to 23 eurocents per $\mathrm{kWh}$ ), wind offshore (7 to 14 eurocents per $\mathrm{kWh}$ ) and onshore (5 to 9 eurocents per $\mathrm{kWh}$ ) as well as fossil fuels (4 to 10 eurocents per $\mathrm{kWh}$ ), consisting of upper and lower limit COE for lignite, hard coal and gas fired power plants, were taken from Höfling (2016) and the Global Renewable Energy Status Report (REN21, 2017). Hereby, newly installed RE plant costs vary widely, depending on site quality, specific economic characteristics and direct nor- 
Table 1. Natural gas storage in operation in porous reservoirs in Germany (EID, 2019).

\begin{tabular}{llrrr}
\hline Storage sites & Reservoir type & Depth $(\mathrm{m})$ & $\begin{array}{r}\text { Total gas volume } \\
\left.\text { (Mio. standard } \mathrm{m}^{3}\right)\end{array}$ & $\begin{array}{r}\text { Working gas } \\
\text { (Mio. standard } \mathrm{m}^{3} \text { ) }\end{array}$ \\
\hline Allmenhausen & former gas deposit & 350 & 380 & 62 \\
Bad Lauchstädt & former gas deposit & 800 & 670 & 440 \\
Bierwang & former gas deposit & 1560 & 3140 & 1000 \\
Breitbrunn-Eggstätt & former gas deposit & 1900 & 2075 & 992 \\
Eschenfelden & saline aquifer & 600 & 168 & 72 \\
Frankenthal & saline aquifer & $600-1000$ & 300 & 90 \\
Fronhofen-Illmensee & former oil deposit & $1750-2200$ & 153 & 10 \\
Hähnlein & saline aquifer & 500 & 160 & 80 \\
Inzenham & former gas deposit & $680-880$ & 880 & 425 \\
Rehden & former gas deposit & $1900-2250$ & 7000 & 4400 \\
Sandhausen & saline aquifer & 600 & 60 & 30 \\
Schmidhausen & former gas deposit & 1015 & 310 & 154 \\
Stockstadt & former gas deposit & 500 & 94 & 45 \\
Stockstadt & saline aquifer & 450 & 180 & 90 \\
Uelsen & former gas deposit & $1470-1525$ & 1579 & 860 \\
Wolfersberg & former gas deposit & 2930 & 583 & 365 \\
\hline
\end{tabular}

mal irradiance (DNI) levels of a given location. Thereby, cost differences in the conventional energy production technologies arise rather from varying operating hours (REN21, 2017). Considerable cost uncertainties with respect to conventional energy production technologies are future fuel and $\mathrm{CO}_{2}$ emission fee developments. Variations in pumped storage hydropower costs are also related to site-specific conditions such as catchment geology and hydrogeology, access to transmission grids as well as overall construction costs. According to the Global Renewable Energy Status Report (REN21, 2017) and the National Hydropower Association's Pumped Storage Development Council (PSDC, 2017), the bandwidth of pumped storage costs covers a range of 43 to 149 eurocents per $\mathrm{kWh}$. A cost position of high uncertainty is the charge for transmission interconnection, which was not considered in the suggested cost bandwidth. These costs can range from negligible charges to substantial amounts according to existing transmission line capacities as well as size and distance of new lines (IRENA, 2017). Since pumped hydropower storage is a technology with decades of operating experience, major technology improvements are not anticipated in the future in terms of costs, structures and transformation efficiency (IRENA, 2017). The COE bandwidth for compressed air energy storage systems were derived to be 30 to 55 eurocents per kWh. However, an increased utilization of waste heat from compression is expected to improve average efficiencies by 2030, resulting in further cost reduction (IRENA, 2017). According to the Handbook of Energy Storage for Transmission or Distribution Applications (EPRI, 2002), levelized costs of pumped hydropower storage and compressed air energy storage represent the lowest cost forms of large grid-scale energy storage technologies.
Taking into account costs for energy conversion during the hydrogenation and methanation processes as well as all costs related to $\mathrm{CO}_{2}$ capture and gas storage operation, study caserelated PGP costs can currently not compete with the aforementioned global fossil and onshore/offshore wind energy production technology $\mathrm{COE}$, which are exceeded by $30 \%$ to $80 \%$ (Fig. 2). However, PGP costs are up to $10 \%$ below those of upper limit solar thermal power and photovoltaic $\mathrm{COE}$ as well as up to $80 \%$ below pumped hydropower and compressed air energy storage costs, and thus competitive on the global energy market (Fig. 2).

\section{Discussion and conclusions}

The growing share of wind and solar energy makes it more complex to balance power generation and demand at any time. Due to the variable availability, the need for flexibility increases in order to keep the energy system stable. Flexible, decentralised producers and consumers will keep the dynamic interplay of electricity supply and demand in balance in the future. In that regard, subsurface natural gas storage $\left(\mathrm{CH}_{4}\right.$ - synthetic natural gas, $\left.\mathrm{SNG}\right)$ offers capacities and a state-of-the-art technology to store and reuse wind and solar energy. Combined geological storage could be employed via EGR, with $\mathrm{CH}_{4}$ and $\mathrm{CO}_{2}$ placed in the same reservoir to be mutually working and cushion gas for each other. Due to gas density and viscosity variations with temperature and pressure, storage from $700 \mathrm{~m}$ depth and below will particularly reduce undesired mixing between both gases. 


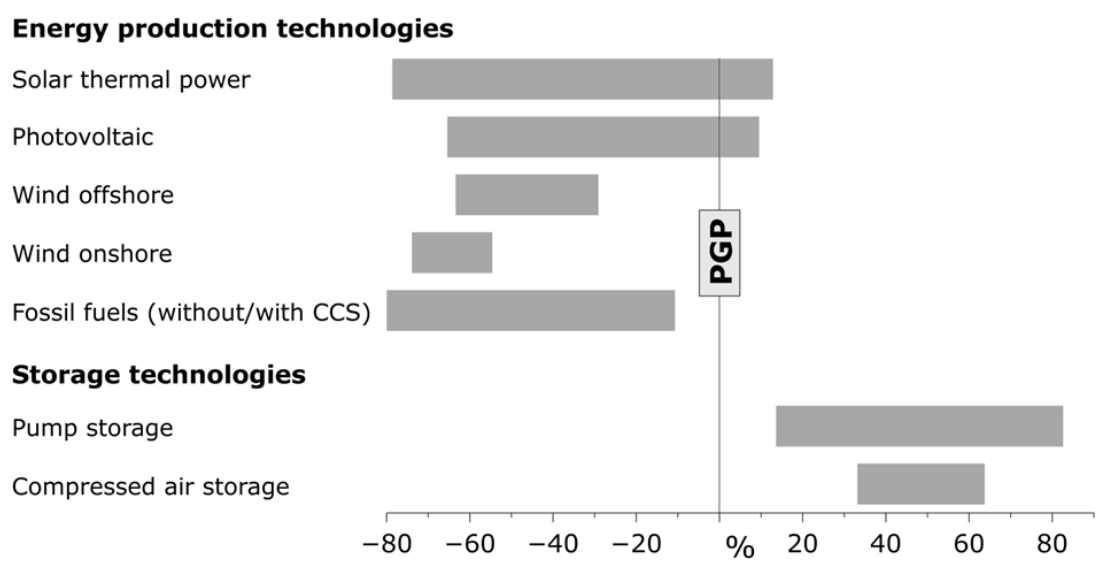

Figure 2. PGP COE (20 eurocents per kWh) compared to global levelized cost bandwidths for fossil fuel and renewable energy production as well as large-grid scale energy storage technologies costs (REN21, 2017; Höfling, 2016; IRENA, 2017).

Natural gas is still the second-most important primary energy source for Germany with a ratio of $24 \%$, with $93 \%$ being imported (EID, 2019). This is why storage facilities play a central role for the entire German energy system. The classic task of subsurface gas storage is the daily and seasonal compensation of consumption peaks. The most recent development in natural gas storage in Germany is characterised by stagnation of the available total working gas volume and an increase in the significance of cavern storage at the expense of porous reservoirs. This resulted in the decommissioning of a couple of high-capacity storage sites within the last years with a storage capacity of around $10 \mathrm{TWh}$ (determined from comparison of EID report 2012 with EID report, 2019). We conclude that these sites should have better been used for excess energy storage from renewables instead of being abandoned, because in that way the storage potential required to date would be covered. On the long run, a storage potential of more than $80 \mathrm{TWh}$ is readily available in the subsurface of Germany, which is actually the amount of excess energy expected for the year 2050 (Sterner and Stadler, 2017). This provides as well an opportunity to significantly reduce the amount of imported natural gas by the provision of "wind and solar gas", which would make Germany more independent of the global market.

Besides the gas storage reservoirs in operation, which we assessed within the presented study, the geological subsurface of Germany provides an even higher, mainly unexplored storage potential. A further estimate can be deduced from investigations in regard to Carbon Capture and Storage (CCS). Knopf et al. (2010) determined a storage capacity of 9 billion tonnes $\mathrm{CO}_{2}$ based on 400 locations. Taking into account the densities of $\mathrm{CO}_{2}$ and $\mathrm{CH}_{4}$ as well as the specific calorific value of the latter, the storage potential is more than 2 orders of magnitude higher (about $30 \mathrm{PWh}$ ) than the one mentioned above.

From the cost data on different energy production and storage technologies compiled for the evaluation of PGP compet- itiveness on the energy market, it becomes obvious that available data provide an uncertain comparative basis, only. Nevertheless, as the objective of the present study was to elaborate a general overview on PGP's current status on the energy market, we have performed a cost comparison and draw the following conclusions. PGP can economically compete with global cost bandwidths for hydropower and compressed air storage as well as with upper limit COE for solar thermal power and photovoltaic. Consequently, future studies on PGP competitiveness should particularly focus on the assessment of, e.g., uncertainties that may impact PGP efficiency.

The technology to store and reuse green excess energy in form of synthetic methane ( $\mathrm{SNG}$ ) is available and ready for operation. It represents the current state-of-the-art and can be applied in the short term. The storage potential within the German subsurface is more than sufficient. Consequently, we have an intermediate option to reduce greenhouse gas emissions as long as hydrogen storage is still under research and development.

Data availability. The underlying data are either given within the paper or elesewhere published and referenced here.

Author contributions. MK conceptualized aims and goals; MK, $\mathrm{NCN}$ and TK conducted the research work; NCN visualised the results; MK wrote the original draft and finalised the paper; $\mathrm{NCN}$ and TK contributed with reviews and editing.

Competing interests. The authors declare that they have no conflict of interest.

Special issue statement. This article is part of the special issue "European Geosciences Union General Assembly 2020, EGU Division 
Energy, Resources \& Environment (ERE)". It is a result of the EGU General Assembly 2020, 4-8 May 2020.

Financial support. The article processing charges for this openaccess publication were covered by the Helmholtz Centre Potsdam, GFZ German Research Centre for Geosciences.

Review statement. This paper was edited by Johannes Miocic and reviewed by three anonymous referees.

\section{References}

acatech: CCU and CCS - Building Blocks for Climate Protection in Industry, Analysis, Options and Recommendations, National Academy of Science and Engineering, acatech Position Paper, available at: available at: https://en.acatech.de/publication/ (last access: 10 November 2020), 2018.

DVGW: Technoökonomische Studie von Power-to-Gas-Konzepten Teilprojekte B-D, DVGW Deutscher Verein des Gas- und Wasserfaches e. V. Technisch-wissenschaftlicher Verein, Abschlussbericht DVGW-FKZ G 3/01/12 TP B-D, available at: https://www.dvgw.de/medien/dvgw/forschung/berichte/g3_01_ 12_tp_b_d.pdf (last access: 10 November 2020), 2014.

EID Energie Informationsdienst $\mathrm{GmbH}$ : Underground Gas Storage in Germany, Erdöl, Erdgas, Kohle, 128, 412-423, https://doi.org/10.19225/191101, 2012.

EID Energie Informationsdienst GmbH: Underground Gas Storage in Germany, Erdöl, Erdgas, Kohle, 135, 415-420, https://doi.org/10.19225/191101, 2019.

EPRI: Handbook of Energy Storage for Transmission or Distribution Applications. Electric Power Research Institute EPRI, USA, available at: http://www.w2agz.com/Library/EPRI_Sources (last access: 10 November 2020), 2002.

Gorre, J., Ruoss, F., Karjunen, H., Schaffert, J., and Tynjälä, T.: Cost benefits of optimizing hydrogen storage and methanation capacities for Power-to-Gas plants in dynamic operation, Appl. Energ., 257, 113967, https://doi.org/10.1016/j.apenergy.2019.113967, 2020.

Hartmann, N., Eltrop, L., Bauer, N., Salzer, J., Schwarz, S., and Schmidt M.: Stromspeicherpotenziale für Deutschland, Zentrum für Energieforschung Stuttgart ZfES, Universität Stuttgart, 2012.

Henning, H.-M. and Palzer, A.: A comprehensive model for the German electricity and heat sector in a future energy system with a dominant contribution from renewable energy technologies Part I: Methodology, Renew. Sustain. Energ. Rev., 30, 10031018, 2014.

Höfling, H.: Kosten der Erneuerbaren Energien - Wie teuer ist der Ökostrom wirklich? Fokus Volkswirtschaft, KfW Research, Nr. 145, Germany, available at: https://www.kfw.de/PDF/DownloadCenter/Konzernthemen/ (last access: 10 November 2020), 2016.

IRENA: Electricity storage and renewables: costs and markets to 2030, International Renewable Energy Agency, Abu Dhabi, available at: https://www.irena.org/publications/ (last access: 10 November 2020), 2017.

Knopf, S., May, F., Müller, C., and Gerling, J. P.: Neuberechnung möglicher Kapazitäten zur $\mathrm{CO}_{2}$-Speicherung in tiefen Aquifer-
Strukturen, Energiewirtschaftliche Tagesfragen, 60, 76-80, 2010 (in German).

Kühn, M.: System and method for ecologically generating and storing electricity, Patent WO 2013156611 A1, available at: https: //patents.google.com/patent/EP2838980A1/en (last access: 1 December 2020), 2013.

Kühn, M., Nakaten, N. C., Streibel, M., and Kempka, T.: Carbon Neutral and Flexible Underground Storage of Renewable Excess Energy, Erdöl, Erdgas, Kohle, 129, 348-352, 2013 (in German).

Kühn, M., Streibel, M., Nakaten, N. C., and Kempka, T.: Integrated underground gas storage of $\mathrm{CO}_{2}$ and $\mathrm{CH}_{4}$ to decarbonise the "power-to-gas-to-gas-to-power" technology, Energ. Proc., 59, 9 15,2014 a.

Kühn, M., Nakaten, N. C., Streibel, M., and Kempka, T.: $\mathrm{CO}_{2} \mathrm{Ge}-$ ological Storage and Utilization for a Carbon Neutral "Powerto-gas-to-power" Cycle to Even Out Fluctuations of Renewable Energy Provision, Energ. Proc., 63, 8044-8049, 2014 b.

Luderer, G.,Vrontisi, Z., Bertram, C., Edelenbosch, O. Y., Pietzcker, R. C., Rogelj, J., De Boer, H. S., Drouet, L., Emmerling, J., Fricko, O., Fujimori, S., Havlik, P., Iyer, G., Keramidas, K., Kitous, A., Pehl, M., Krey, V., Riahi, K., Saveyn, B., Tavoni, M., Van Vuuren, D. P., and Kriegler, E.: Residual Fossil $\mathrm{CO}_{2}$ Emissions in $1.5-2{ }^{\circ} \mathrm{C}$ Pathways, Nat. Clim. Change, 8, 626-633, 2018.

Ma, J., Qi, L., Kempka, T., and Kühn, M.: Hydromechanical Response and Impact of Gas Mixing Behavior in Subsurface $\mathrm{CH}_{4}$ Storage with $\mathrm{CO}_{2}$ Based Cushion Gas, Energ. Fuels, 33, 65276541, 2019

Metz, B., Davidson, O., de Coninck, H. C., Loos, M., and Meyer, L. A.: Special report on carbon dioxide capture and storage prepared by working group III of the intergovernmental panel on climate change (IPCC), Cambridge University Press, Cambridge, 2005.

Nakaten, N. C., Schlüter, R., Azzam, R., and Kempka, T.: Development of a techno-economic model for dynamic calculation of cost of electricity, energy demand and $\mathrm{CO}_{2}$ emissions of an integrated UCG-CCS process, Energy, 66, 779-790, 2014.

PSDC: Challenges and Opportunities For New Pumped Storage Development, A White Paper Developed by National Hydropower Association's (NHA) Pumped Storage Development Council, available at: https://www.hydro.org/wp-content/ uploads/2017/08/NHA_PumpedStorage_071212b1.pdf (last access: 10 November 2020), 2017.

Renewable Energies Agency: https://www.unendlich-viel-energie. de/english, last access: 10 November 2020.

REN21: Global Status Report. Renewable Energy Policy Network for the 21st Century, Paris, available at: https://de.scribd.com/document/377754637/ 17-8399-GSR-2017-Full-Report-0621-Opt-pdf (last access: 10 November 2020), 2017.

Sterner, M. and Stadler, I.: Energiespeicher - Bedarf, Technologien, Integration, Springer Publishers, 2017

Streibel, M., Nakaten, N. C., Kempka, T., and Kühn, M.: Analysis of an Integrated Carbon Cycle for Storage of renewables, Energ. Proc., 40, 202-211, 2013.

van der Meer, B.: Carbon dioxide storage in natural gas reservoirs, Oil \& Gas Science and Technology - Rev. IfP, 60, 527-536, 2005. 